\title{
Renal failure in a patient with chronic lymphocytic leukaemia treated with fludarabine
}

\author{
M P Macheta, L A Parapia, D R Gouldesbrough
}

\begin{abstract}
The case history of a man with refractory chronic lymphocytic leukaemia who developed acute renal failure following treatment with fludarabine is presented. A renal biopsy specimen showed features of mesangiocapillary glomerulonephritis, a rare occurrence in chronic lymphocytic leukaemia. The rapid cytocidal action of fludarabine may result in the development of renal glomerular lesions when used to treat a well differentiated $B$ cell malignancy.

(F Clin Pathol 1995;48:181-182)
\end{abstract}

Keywords: Fludarabine, renal failure, chronic lymphocytic leukaemia.

\section{Case Report}

In 1987, a 60 year old man presented with lymphadenopathy and lymphocytosis. A diagnosis of chronic lymphocytic leukaemia (CLL) was reached following examination of bone marrow, and peripheral blood lymphocyte marker studies. Three years later, the patient developed increasing superficial lymphadenopathy and enlarged tonsils. This resolved completely after three months of treatment with chlorambucil and prednisolone. In 1992, lymphadenopathy recurred with increasing lymphocytosis (white blood cell count $104 \times$ $10^{9} / 1$ ). Lymphadenopathy progressed despite treatment with chlorambucil and prednisolone for three months. Treatment with fludarabine was then started at a dose of $25 \mathrm{mg} / \mathrm{m}^{2}$ daily (43 mg/day) for five days every four weeks. The patient had a history of ischaemic heart disease and was taking frusemide, nifedipine and warfarin.

On admission for the fifth course of fludarabine, the patient complained of exertional dyspnoea, orthopnoea and oliguria. On examination, there were signs of congestive cardiac failure. There was no lymphadenopathy or hepatosplenomegaly. Urinalysis revealed proteinuria and haematuria. Standard laboratory analyses revealed the following: haemoglobin $11.6 \mathrm{~g} / \mathrm{dl}$; white blood cell count $6.4 \times 10^{9} / \mathrm{l}$; platelets $133 \times 10^{9} / \mathrm{l}$; sodium $139 \mathrm{mmol} / \mathrm{l}$; potassium $4.1 \mathrm{mmol} / 1$; urea $9.0 \mathrm{mmol} / \mathrm{l}$; creatinine $145 \mu \mathrm{mol} / \mathrm{l}$; urate $610 \mu \mathrm{mol} / 1$ (normal range $250-500 \mu \mathrm{mol} / 1$ ); albumin $34 \mathrm{~g} / \mathrm{l}$; and globulin $28 \mathrm{~g} / \mathrm{l}$. A chest $x$ ray film revealed cardiomegaly and interstitial pulmonary oedema. No casts were observed on urine microscopy. C3 $0.39 \mathrm{~g} / 1$ (normal range $0.75-1.65 \mathrm{~g} / 1$ ); C4 $0.08 \mathrm{~g} / 1$ (normal range 0.2 $0.65 \mathrm{~g} / \mathrm{l})$; antibodies to glomerular basement membrane and double stranded DNA, antineutrophil cytoplasm antibody, and cryoglobulins were negative; no paraproteins were detected on serum electrophoresis; bone marrow examination revealed no evidence of CLL or lymphoma; and ultrasonography showed both kidneys and urinary tracts to be normal. Treatment with diuretics, fluid restriction and allopurinol was instituted. Renal function continued to deteriorate rapidly and 10 days later the patient's creatinine concentration was raised further: $652 \mu \mathrm{mol} / 1$. Percutaneous renal biopsy was performed. There was no improvement following daily pulses of intravenous methylprednisolone (1 g) and oral cyclophosphamide $(75 \mathrm{mg})$. Peritoneal dialysis was started and the patient is currently undergoing regular haemodialysis.

On light microscopy, the renal biopsy showed focal accentuation of glomerular lobular architecture, a focal and segmented increase in mesangial cellularity and focal thickening of glomerular basement membranes. Tubules and blood vessels appeared normal. Immunofluorescence microscopy revealed coarse granular deposits of $\mathrm{C} 3$ within the basement membrane in some glomeruli and mesangial deposition in others. Irregular granular deposits of IgM were also present in the basement membrane. On electron microscopy, there were patchy subendothelial electron dense deposits and elongated deposits in some areas of thickened basement membrane (figure). No mesangial cell interposition was identified and there was no evidence of interstitial cellular infiltrate.

\section{Discussion}

There have been 44 published reports of renal glomerular disease associated with CLL and well differentiated B cell non-Hodgkin's lymphoma..$^{1-5}$ Mesangiocapillary glomerulonephritis (MCGN) is the most common glomerular lesion reported, occurring in eight of the 11 patients with CLL and nephrotic syndrome described by Moulin et al. ${ }^{2}$ However, the spectrum of glomerular lesions described is wide and includes membranous and minimal change glomerulonephritis, focal segmental glomerulosclerosis and amyloidosis. Although the pathological changes in this case were atypical they most closely resemble those present in type I MCGN. In this case complete remission of CLL had been achieved when renal failure developed. However, Korzets et al noted that the stage of CLL and onset of glomerular disease were not necessarily related.

Immune complex deposition is thought to 


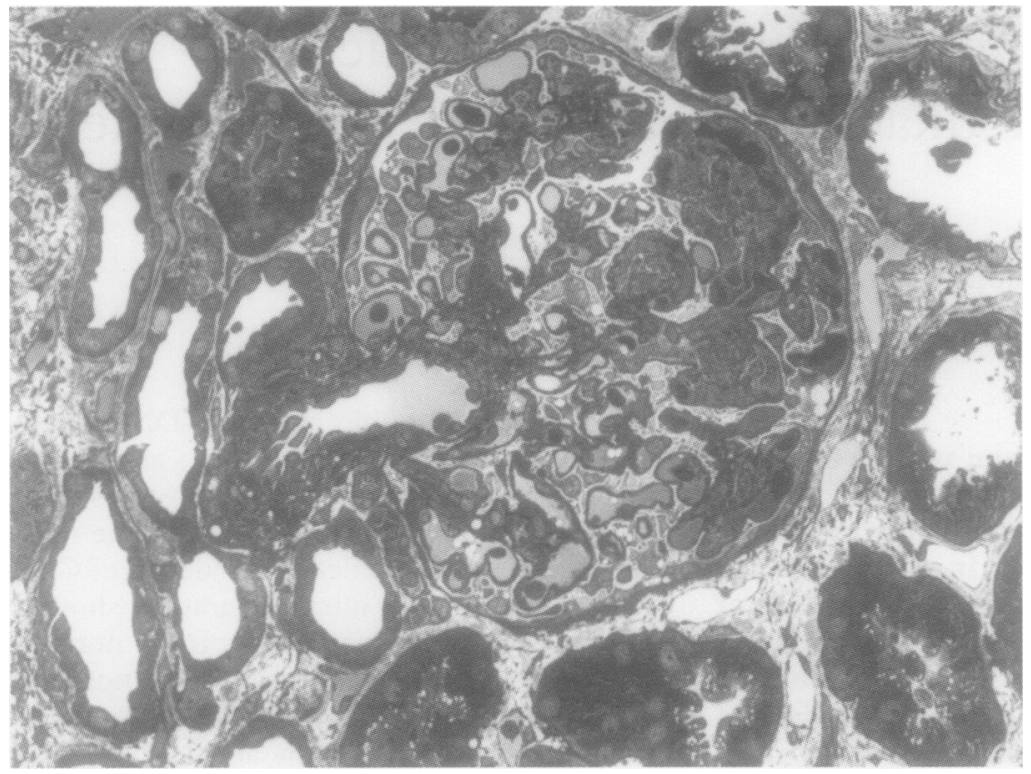

A medium power photomicrograph illustrating the segmental accentuation of the lobular architecture of the glomeruli $(P A M S \times 250)$.

be the initiating event in MCGN. ${ }^{6}$ CLL and well differentiated B cell non-Hodgkin's lymphoma are associated with abnormalities of immunoglobulin production and autoimmunity. In those cases where glomerular disease develops there is often evidence of $\mathrm{M}$-protein production by the proliferating $B$ cell clone. In a series of patients with CLL and MCGN one third had circulating $\mathrm{M}$-protein compared with $5-10 \%$ of all patients with CLL. Cryoglobulinaemia and evidence of complement consumption are also common. ${ }^{1}$ Monotypic immunoglobulin or light chain deposition has been demonstrated within glomeruli by immunofluorescence even in the absence of circulating M-protein, strengthening the aetiological link between monoclonal lymphoid proliferation and glomerular disease. ${ }^{2}$

In the series of patients with $\mathrm{CLL} /$ well differentiated B cell non-Hodgkin's lymphoma and glomerular disease reported by Moulin et $a l^{2} 10$ of the 13 patients were treated with chlorambucil and prednisolone. In six of seven patients with MCGN, treatment induced complete remission of glomerular disease (chlorambucil alone was used in five patients). In seven of eight patients with renal failure there was a substantial improvement in renal function even though five of these patients had MCGN, a condition which normally has a poor prognosis. In one case where repeat renal biopsy was performed following treatment with chlorambucil there was improvement in the histological features of MCGN. All three patients with MCGN, or atypical membranous glomerulonephritis, and CLL described by Touchard et $a^{\beta}$ improved, attaining remission after treatment with chlorambucil and pred- nisolone. Spontaneous remission of glomerular disease associated with CLL may also occur ${ }^{4}$ and successful treatment with interferon has been described. ${ }^{5}$

Fludarabine is a purine analogue. It is an effective, rapidly cytocidal agent for the treatment of refractory CLL and well differentiated B cell non-Hodgkin's lymphoma. ${ }^{78}$ The major reported side effects are myelosuppression and demyelination. Although renal failure caused by tumour lysis following treatment with fludarabine is well documented, ${ }^{9}$ direct nephrotoxicity or glomerular disease have not been described. The suppliers have received reports of five other patients with CLL/well differentiated B cell non-Hodgkin's lymphoma in whom renal failure developed after treatment with fludarabine. None of these patients underwent renal biopsy. Two were similar to this case in that acute renal failure developed three weeks after the second course of treatment. The release of a large amount of leukaemic cell antigen as a result of the rapid cytocidal action of fludarabine may predispose patients to the formation of the immune complexes responsible for glomerular injury. Acute renal failure is an unusual symptom of MCGN and in the case presented here cardiac and vascular insufficiency may also have contributed to the rapid decline in renal function.

Haematologists should be aware of the rare association of well differentiated B cell lymphoproliferative disorders with renal glomerular disease because, with increasing use of fludarabine, such cases may occur more frequently. Furthermore, the onset of renal glomerular disease may be a further indication for treatment in CLL and well differentiated B cell non-Hodgkin's lymphoma given the excellent response observed in many cases.

1 Seney FD, Federgreen WR, Stein H, Kashgarian M. A review of the nephrotic syndrome associated with chronic lymphocytic leukaemia. Arch Intern Med 1986;146:137-41. Moulin B, Ronco PM, Mougenot B, Francois A, Fillastre J, Mignon F. Glomerulonephritis in chronic lymphocytic leukaemia and related B-cell lymphomas. Kidney Int 1992 42:127-35.

3 Touchard G, Preud'homme JL, Aucouturier P, Giraud C, Fouet D, Yver L, et al. Nephrotic syndrome associated with chronic lymphocytic leukaemia: an immunological with chronic lymphocytic leukaemia: an immunologica

4 Korzets Z, Elis A, Bernheim J, Ravid M, Bernheim J. Mesangiocapillary glomerulonephritis associated with chronic lymphocytic leukaemia: a therapeutic dilemma. chronic lymphocytic leukaemia: a the

5 Nakayama S, Yabe H, Nagai K. Nephrotic syndrome associated with chronic lymphocytic leukaemia successfully treated with interferon-alpha. $尹 p n \mathcal{F}$ Clin Haematol 1990 31:1924-8.

6 D'Amico G, Ferrario F. Mesangiocapillary glomerulonephritis. f Am Soc Nephrol 1992;2:(Suppl 10) 159-66.

7 Keating MJ, Kantarjian H, Talpaz M, Redman J, Koller C, Barlogie $\mathrm{B}$, et al. Fludarabine: a new agent with major activity against chronic lymphocytic leukaemia. Blood 1989; 74:19-25.

8 Whelan JS, Davis CL, Rule S, Ranson M, Smith OP, Mehta $\mathrm{AB}$, et al. Fludarabine phosphate for the treatment of low AB, et al. Fludarabine phosphate for the treatment of low

grade lymphoid malignancy. Br f Cancer 1991;64:120-3.
List AF, Kummett TD, Adams JD, Chun HG. Tumour lysis List AF, Kummett TD, Adams JD, Chun HG. Tumour lysis
syndrome complicating treatment of chronic lymphocytic syndrome complicating treatment of chronic lymphocytic 89:388-90. 